\title{
Factors Affecting Nurses' Customer Orientation
}

\author{
Jun-Hee Park ${ }^{1}$, Jeong-Won Han ${ }^{2 *}$ and Young-Ran Yeun ${ }^{3}$ \\ ${ }^{1}$ College of Nursing Science, Kyunghee University, E-mail: \\ ${ }^{2}$ College of Nursing, Kosin University \\ ${ }^{3}$ Department of Nursing, Kangwon National University \\ lwiwi78@kyunghee.ac.kr,*2hjw0721@kosin.ac.kr, ${ }^{3}$ yeunyr@kangwon.ac.kr,
}

\begin{abstract}
This study aimed to identify the factors affecting nurses' customer orientation. A survey was conducted on 440 nurses working for general hospitals in South Korea from November 22 through December 15, 2012, and this study analyzed the data from the questionnaire with SPSS Windows 18.0. Data were analyzed using t-test, analysis of variance, Pearson's correlation, and multiple regression. All factors had a significant correlation with customer orientation. Multiple multiple regression analysis revealed that self-leadership and deep acting was the factor positively influencing nurses' customer orientation. These factors explained $54.0 \%$ of customer orientation. It has important implications in that it suggests a customer orientation prediction model that hospital managers can use as baseline data for nursing human resource management.
\end{abstract}

Keywords: Leadership, Culture, Emotion, Customer

\section{Introduction}

In recent years, according to increasing the social interest in health and wellness, large companies have become involved in the hospital business. The environment of medical service providers is becoming more and more competitive. Recently patients have more options than before [1] and hospital has increased to focus on consumer-centeredness [2]. In the past, medical consumers considered only the superiority of medical staff when choosing a medical center and received medical services from a passive position. However, modern medical consumers take an active role in selecting medical centers that provide high-quality human, material, and institutional resources by searching for information via various media [3] The delivery of medical service is more complex between medical consumers and service suppliers, unlike general service, that the customer service challenge is therefore greater. In addition, because human services play a major role in determining the service quality of medical centers, customer satisfaction management strategies that satisfy the needs of consumers through human resources are increasing the competitiveness of medical centers [4].

Among the various customer satisfaction management strategies of medical centers, customer orientation is an organizational behavior designed to create a competitive advantage by constantly providing better services based on the needs of customers [3]. Customer orientation consists of reliability, tangibility, responsiveness, and empathy. Reliability refers to the ability to precisely and reliably perform an appointed service; tangibility refers to external service quality;

*Corresponding Author: Jeong-won Han

Assistant Professor, College of Nursing, Kosin University, 262 Gamcheon-ro, Seo-gu, Busan $602-$ 703, Korea 
responsiveness refers to willingness to help customers and quickly provide services; and empathy refers to sufficiently understanding and communicating with customers, along with the feasibility of using services [2]. Customer orientation can be embodied by organization members, and customer-oriented attitudes have a positive effect on long-term relationships with customers. In particular, because customers using medical services may have a high level of mental anxiety due to illhealth, customer-oriented attitudes play a major role in influencing the medical service utilization behaviors of customers by relieving anxiety and maintaining ongoing relationships [5]. Customer orientation was influence by individual factors, which is self-leadership, emotional labor and organizational levels, such as organizational culture. In nursing sector, however, only fragmentary studies have been made with respect to customer orientation [6-8]. Some studies have shown associations between customer orientation and self-leadership [2, 9-11], customer orientation and emotional labor [1213], customer orientation and organizational culture [2, 14]. However, several other studies have not established a link between customer orientation and other factors.

\section{Methods}

\subsection{Sample}

This study was approved by the ethics commission of the affiliated organization (IRB, No. IRB2012-S17) and targeted nurses in three general hospitals with more than 400 beds who gave written consent to participate. To verify the statistical power of our sample size, we used the $G^{*}$ power 3.1.7 program [15]. The sample size required in multiple regression method was 370 with the following parameters. This study included 440 participants in order to take into consideration negligent respondents.

\subsection{Measurement}

\subsubsection{Customer Orientation}

Fourteen questions (answered using a 7-point scale) developed by Parasuramn, Zeithml and Berry [16] and adapted and modified by Moon [17] were selected for this study after conducting validity verification. The questions consisted of 3 reliability questions $(\alpha=0.84), 4$ on responsiveness $(\alpha=0.86), 3$ on tangibility $(\alpha=0.84)$, and 4 on empathy $(\alpha=0.83)$. The score range was $1-7$, with a higher value representing a higher level of customer orientation. Cronbach's alpha was 0.80 in Moon's study [17] and 0.83-0.86 in this study.

\subsubsection{Self-leadership}

Ten questions developed by Houghtom and Neck [18] and verified by Park, Yun, and Han [19] (construct validity) were used, and they consisted of 2 self-compensation questions $(\alpha=0.82), 3$ on self-disciplinary punishment $(\alpha=0.70), 2$ on self-observation $(\alpha=0.79)$, and 3 on self-talk $(\alpha=0.83)$. The score range was $1-5$, with a higher value representing a higher level of self-leadership. Cronbach's alpha was 0.83 in the study by Park et al. [19] and 0.70-0.75 in the present study.

\subsubsection{Organizational Culture}

This study verified the construct validity of a tool with which Kim and Park [20] classified organizational culture into innovation-oriented culture, relation-oriented culture, task-oriented culture, and hierarchy-oriented culture based on the competing value model of Quinn and McGrath [21] and created 13 questions (5-point scale) consisting of 3 relation-oriented culture questions $(\alpha=0.70), 4$ on innovation- 
oriented culture $(\alpha=0.72), 4$ on hierarchy-oriented culture $(\alpha=0.73)$, and 2 on joboriented culture $(\alpha=0.67)$. The score range was $1-5$, with a higher value representing a higher level of organizational culture. Cronbach's alpha was 0.73-0.84 in the study by Kim and Park [20] and 0.67-0.73 in the present study.

\subsubsection{Emotional Labor}

A total of 11 questions (7-point scale) developed by Brotheridge and Lee [22] and adapted and modified by Yi, Gim, and Shin [23] were used and were divided into five surface acting and six deep acting questions. The score range was 1-7, with a higher value representing a higher level of emotional labor. Cronbach's alpha was $0.88-0.89$ in the study by Yi et al. [23] and 0.81-0.87 in the present study.

\subsection{Data Analysis}

In the current study, an expert group made up of 2 nursing professors and 3 doctoral students presently working in a clinical setting modified and supplemented each tool and verified the content validity index [CVI], which showed a range of .81-.88. The present study collected data from November 22, 2012 to December 15,2012 by distributing self-report questionnaires to 440 nurses in three general hospitals with more than 400 beds who gave written consent to participate. In total, 410 questionnaires $(93.1 \%)$ were returned, of which, 399, excluding 11 that contained insufficient responses, were used for the actual analysis data. This study used SPSS Windows 18.0 (SPSS Korea Data solution Inc.) to analyze the collected data. The correlations between customer orientation and the variables were analyzed through Pearson's correlation. The customer orientation predictor variables were analyzed using multiple regression.

\section{Results}

\subsection{General Characteristics of Research Subjects}

The average age of participants was 32.3 years, with 93 persons $(23.4 \%) \leq 25$ years old, $114(28.6 \%)$ subjects between 26-30 years, 69 (17.2\%) between 31-35 years, and $123(30.8 \%) \geq 36$ years. For academic background, the number of persons who graduated from three-year colleges was $111(27.8 \%), 229(57.5 \%)$ graduated from four-year colleges, and $59(14.7 \%)$ attended graduate school or higher. Of the respondents, 211 persons $(53.0 \%)$ answered they had a religious affiliation, and $188(47.0 \%)$ reported no such affiliation; $186(46.5 \%)$ participants were married and $213(53.5 \%)$ were not. With respect to intention to move to another unit, 259 (64.8\%) participants answered 'no' and $140(35.2 \%)$ answered 'yes,' while $183(45.8 \%)$ reported no experience in other units and $216(54.2 \%)$ had moved among units. The average total work experience of the participants was 9.4 years; 84 persons $(21.1 \%)$ had $\leq 3$ years of work experience, $110(27.5 \%)$ had $3-8$ years of work experience, $83(20.8 \%)$ had $8-13$ years of work experience, and 122 $(30.6 \%)$ had $\geq 13$ years of work experience. The average years of experience in the present unit was 3.95 years, with 59 persons $(14.7 \%)$ with $\leq 1$ year of experience, 97 (24.4\%) with $1-3$ years, $121(30.3 \%)$ with $3-5$ years, and $122(30.6 \%)$ with $\geq 5$ years of experience. With regard to position, $358(89.7 \%)$ were staff nurses and 41 $(10.3 \%)$ were charge nurses or higher; with regard to shift pattern, 268 persons $(67.1 \%)$ worked three rotating shifts and 131 (32.9\%) worked two rotating shifts or did not work in shifts. With regard to unit satisfaction, 202 respondents $(50.6 \%)$ answered that they were 'satisfied,' 163 (40.8\%) 'moderate,' and 34 (8.5\%) 'unsatisfied.' (Table 1). 
Table1. The General Characteristics of Subjects

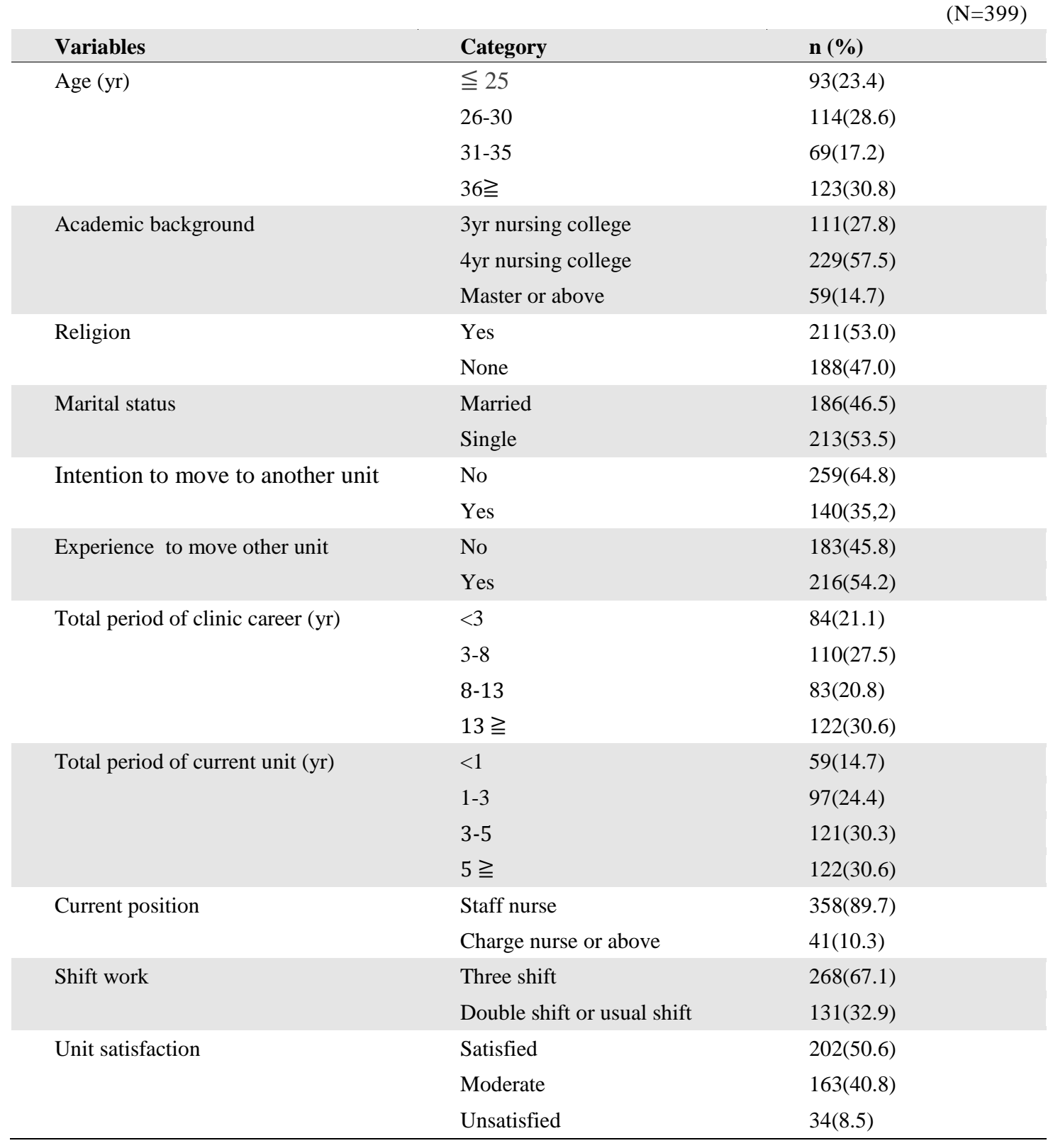

\subsection{Factors Correlating with Nurse's Customer Orientation}

A significant correlation was observed between self-punishment and selfobservation $(\mathrm{r}=0.44, \mathrm{p}<0.001)$, self-dialogue $(\mathrm{r}=0.38, \mathrm{p}<0.001)$, relation-oriented culture $(r=0.10, p<0.05)$, innovative culture $(r=0.19, \mathrm{p}<0.05)$, hierarchical culture $(\mathrm{r}=0.19, \mathrm{p}<0.001)$, surface acting $(\mathrm{r}=0.20, \mathrm{p}<0.001)$, deep acting $(\mathrm{r}=0.17, \mathrm{p}<0.001)$, trust $(r=0.24, p<0.001)$, response $(r=0.21, p<0.001)$, appearance $(r=0.20, p<0.001)$, sympathy $(\mathrm{r}=0.24, \mathrm{p}<0.001)$. In other words, self punishment increased as self observation, self dialogue, relation-oriented culture, innovative culture, hierarchical culture, surface acting, deep acting, trust, response, appearance, sympathy increased (Table 2). 
Table 2. Correlation Among the Variables

\begin{tabular}{|c|c|c|c|c|c|c|c|c|c|c|c|}
\hline $\begin{array}{l}\text { Varia } \\
\text { bles }\end{array}$ & X1 & $\mathrm{X} 2$ & $\mathrm{X} 3$ & $\begin{array}{l}\mathrm{X} 4 \mathrm{X} 5 \\
\end{array}$ & $\mathrm{X} \epsilon$ & $\mathrm{X} 7$ & X8 & $\times 9$ & $\mathrm{X} 10$ & $\mathrm{X} 11$ & \\
\hline X2 & $0.44^{*}$ & & & & & & & & & & \\
\hline X3 & $0.38^{*}$ & $0.39^{*}$ & & & & & & & & & \\
\hline $\mathrm{X} 4$ & $0.10^{*}$ & $0.29^{*}$ & $0.25^{*}$ & & & & & & & & \\
\hline X5 & $0.19^{*}$ & $0.31^{*}$ & $0.26^{*}$ & $0.70^{*}$ & & & & & & & \\
\hline X6 & $0.19^{*}$ & $0.24^{*}$ & $0.18^{*}$ & $0.60^{*}$ & $0.74^{*}$ & & & & & & \\
\hline $\mathrm{X} 7$ & $0.20^{*}$ & $0.12^{*}$ & 0.01 & $0.14^{* *}$ & $0.16^{-* *}$ & -0.09 & & & & & \\
\hline X8 & $0.17^{*}$ & $0.41^{*}$ & $0.24^{*}$ & $0_{*}$ & $0.34^{*}$ & $0.24^{*}$ & $0.16^{*}$ & & & & \\
\hline X9 & $0.24^{*}$ & $0.46^{*}$ & $0.24^{*}$ & $0.23^{*}$ & $0.29^{*}$ & $0.26^{*}$ & $0.50^{*}$ & -0.04 & & & \\
\hline X10 & $0.21^{*}$ & $0.43^{*}$ & $0.27^{*}$ & $0.26^{*}$ & $0.30^{*}$ & $0.29^{*}$ & $0.55^{*}$ & $0.78^{*}$ & 0.04 & & \\
\hline X11 & $0.20^{*}$ & $0.42^{*}$ & $0.25^{*}$ & $0.21^{*}$ & $0.26^{*}$ & $0.26^{*}$ & $0.55^{*}$ & $0.67^{*}$ & $0.71^{*}$ & 0.04 & \\
\hline X12 & $0.24^{*}$ & $0.47^{*}$ & $0.31^{*}$ & $0.31^{*}$ & $0.31^{*}$ & $0.28^{*}$ & $0.56^{*}$ & $0.68^{*}$ & $0.75^{*}$ & $0.76^{* *}$ & $\begin{array}{r}0 \\
.04 \\
\end{array}$ \\
\hline
\end{tabular}

$* p<0.05 * * p<0.001$

$\mathrm{X} 1=$ Self punishment; $\mathrm{X} 2=$ Self observation; $\mathrm{X} 3=$ Self dialogue; $\mathrm{X} 4=$ Relation-oriented culture; $\mathrm{X} 5=$ =nnovative culture; X6=Hierarchical culture; X7=Surface acting; X8=Deep acting; $X 9=$ Trust; $X 10=$ Response; X11=Appearance; X12=Sympathy

\subsection{Factors Affecting Nurses' Customer Orientation}

To identify the variables affecting nurses' customer orientation, multiple regression analysis was performed. The independent variables is self-leadership, emotional labor (deep acting and surface acting) and organizational culture. The results are shown in Table 3. Self-leadership $(\beta=0.69, p<0.001)$ and deep acting $(\beta=0.31$, $\mathrm{p}<0.001)$ had showed a statistically significant effect in nurses' customer orientation, it had an effect on the increase in customer orientation. The total explanatory adequacy of these factors was 54\% ( $\mathrm{F}=90.85, \mathrm{p}<0.001)$ (Table 3). While organizational culture $(\beta=0.05, \mathrm{p}=0.409)$ and surface acting $(\beta=-0.02, \mathrm{p}=0.410)$ had no effect in nurses' customer orientation. The Durbin-Watson test score was 1.537 with no correlations among residuals. No variables exhibited multicollinearity: tolerance ranged from 0.77 to 0.96 and variance inflation factor (VIF) ranged from 1.04 to 1.31 , which showed that no variables exhibited multicollinearity. Therefore, it appeared that a regression model would be appropriate.

Table 3. Factors Affecting Nurses' Customer Orientation

\begin{tabular}{|c|c|c|c|c|c|c|c|}
\hline Variables & B & S.E & $B$ & $\mathbf{t}$ & $\begin{array}{l}\text { Adjust } \\
\text { ed } R^{2}\end{array}$ & $\mathbf{F}$ & $p$ \\
\hline $\begin{array}{c}\text { Self- } \\
\text { leadership }\end{array}$ & 0.40 & 0.13 & 0.69 & $5.22^{*}$ & \multirow{4}{*}{0.54} & \multirow{4}{*}{90.85} & \multirow{4}{*}{$\begin{array}{l}<0.0 \\
01\end{array}$} \\
\hline $\begin{array}{l}\text { Organizationa } \\
1 \text { culture }\end{array}$ & 0.04 & 0.06 & 0.05 & .083 & & & \\
\hline Surface acting & -0.04 & 0.03 & -0.02 & -.82 & & & \\
\hline Deep acting & 0.43 & 0.04 & 0.31 & $8.12^{*}$ & & & \\
\hline
\end{tabular}




\section{Discussion}

The purpose of the present study was to investigate nurses' customer orientation and its influential factors. First, looking at the relationship between self-leadership and emotional labor, a significant correlation was observed between self-leadership and emotional labor. This result is similar to that of a previous study [2] that found that selfleadership of nurses was related to the emotional labor of members. In other words, because self-leadership of nurses is a behavioral and cognitive strategy used to influence themselves [24], it can play a role as a self-leading and self-motivating factor that can control the emotions that occur during the process of delivering services [11]. Thus, it is expected that, if hospital managers create and actively use programs promoting selfleadership for nurses, customer satisfaction could be improved by nurses who play roles as important mediators of medical services. However, the result that self-leadership increases surface acting as well as deep acting should be confirmed through further research on the causal relationship between self-leadership and emotional labor.

Second, a significant correlation was observed between organizational culture and emotional labor. This result is similar to that of a preceding study targeting secretaries [25] that found differences in the emotional labor of members depending on the organizational culture, even in the same kind of job. Because organizational culture is unique values, faiths, norms, customs, and behavioral patterns shared by organization members [26], also affects organizational performance and innovation, particularly in service industries [14], it is of strategic importance for managers to pay attention to organizational culture. Therefore, it may be possible to improve customer satisfaction by decreasing the emotional labor of members if hospital managers, responding to dramatically changing environments, create, maintain, and develop unique organizational cultures. In addition, further research is needed in order to discern what types of organizational culture affect emotional labor in detail.

Third, examining the factors that influence customer orientation, all factors had a significant correlation with customer orientation, self-leadership and deep acting had effects on customer orientation, but organizational culture and surface acting had no effect on customer orientation. This result is similar to that of a previous study [9] that found that the self-leadership of hotel employees influenced customer orientation and another study [13] that found that the emotional labor of hotel employees influenced the customer orientation. In addition, the study confirmed the results of Oh and Yook [10], which found that, because the needs of customers are constantly changing in service fields and prompt delivery of service increases customer satisfaction, relationships with customers can be maintained only when using a service delivery system that is controlled and led by members in the service encounter. Moreover, the fact that, for deep acting, individual efforts to deliver specific emotions to customers, as well as external expressions of emotions required by the organization, are important for outstanding customer service [25] was also reconfirmed in this study.

However, previous research targeting police officers [27] and railway officials [14] reported that organizational culture had an effect on customer orientation. This result indicates that, because medical service deals with customer's health even lives unlike other public service, medical customer requires high-quality human medical service such as hospital members to be various roles with active attitude [3]. It is difficult to increase the customer orientation of members to just use organizational culture. However, if methods of controlling emotional labor based on organizational culture can be shared, customer orientation may increase. Thus, hospital managers need to utilize self-leadership training and emotion control training by forming a unique organizational culture to increase the customer orientation level of members. Our findings provide a better understanding of nurses' customer orientation and establish basic data for nursing service. 
However, because there are only a few studies targeting nurses with regard to the effects of self-leadership and organizational culture on customer orientation, research on the causal relationships among those factors and on various other factors that influence the customer orientation of nurses should be conducted in the future.

\section{Conclusion}

Through multiple regression analysis, this study examined factors that influence the customer orientation of nurses. The study found that self-leadership and deep acting had significant effects on the increases in nurses' customer orientation. And, significant correlation was observed between nurses' customer orientation and organizational culture, surface acting, but these factors had no effect on customer orientation.

\section{Acknowledgments}

The present authors would like to thank all those who participated in this study.

\section{References}

[1] W. I. Lee, C. W. Chen, T. H. Chen and C. Y. Chen, "The Relationship between Consumer Orientation, Service Value, Medical Care Service Quality and Patient Satisfaction: The Case of a Medical Center in Southern Taiwan", AJBM, vol. 4, no. 4, (2010), pp. 445-458.

[2] I. K. Hong, "Nurse's Customer Orientation and Influential Factors", Unpublished masters's thesis, University of Kyung Hee University, Seoul, Korea, (2011).

[3] S. Y. Ahn and S. Y, "The Effect of Perceived Organization Support on Hospital Employees' Attitude", J Korea Acad Industr Coop Soc, vol. 11, no. 3, (2010), pp. 1115-1125.

[4] Y. K. Kim and M. S. Seo, "The Impact of the Nonverbal Communication of the Medical Service Provider on the Customer Satisfaction and Customer Behavior", Journal of Consum. Cult, vol. 9, no. 3, (2006), pp. 155-184.

[5] J. L. Chandon, P. Y. Leo and J. Philippe, "Service Encounter Dimensions - A Dynamics Perspective: Measuring the Dimensions of Service Encounters as Perceived by Customers and Personnel", International Journal Serv Ind Manag, vol. 8, no. 1, (1977), pp. 65-86.

[6] J. Choi and N. S. Ha, "The Effects of Clinical Nurse`s Internal Marketing on Job Satisfaction, Turnover Intention, and Customer Orientation”, Jouranl Korean Acad Nurs Adm, vol. 13, no. 2, (2007), pp. 231241.

[7] M. Y. Kim and E. S. Do, "Comparison of Internal Marketing, Job Satisfaction and Customer Orientation of Nurses by Size of Medical Care Institution; Small-medium Hospitals and General Hospitals", Journal Korean Acad Nurs Adm, vol. 18, no .1, (2012), pp. 56-66.

[8] Y. S. Lee and M. S. Jung, "Relationship of Followership to Organizational Commitment, Job Satisfaction, Turnover Intention and Customer Orientation in Nurses", Journal Korean Acad Nurs Adm, vol. 19, no. 2, (2013), pp. 187-195.

[9] Y. T. Kim, S. H. Kim and K. H. Choi, "An Empirical Study on Self-leadership, Job Satisfaction and Customer Orientation of Employees in Hotel Industry: Moderating Role of Organizational Commitment”, Korean Journal Culinary Res, vol. 17, no. 2, (2011), pp. 182-197.

[10] E. J. Shin and Y. S. Park, “ Emotional Intelligence, Ego Resilience, Stress in Clinical Practice of Nursing Students, Journal Korea Acad Industr Coop Soc, vol. 14, no. 11, (2013), pp. 5636-5645.

[11] Y. R. Yeun, "Effects of Comprehensive Nursing Service on the Nursing Performance, Job Satisfaction and Customer Orientation among Nurses", Journal Korea Acad Industr Coop Soc, vol. 16, no. 1, (2015), pp. 317-323.

[12] A. S. Gabriel, M. A. Daniels, J. M. Diefendorff and G. J. Greguras, "Emotional Labor Actors: A Latent Profile Analysis of Emotional Labor Strategies", Journal Appl Psychol, vol. 100, no. 3, (2015), pp. 863879.

[13] S. N. Hong, B. H. Choi and M. S. Kim, "Investigating the Structural Relationships among Hospitality Industry Employee's Job Resources, Burnout, Depersonalization, and Customer Orientation", Journal Korea Acad Industr Coop Soc, vol. 16, no. 3, (2015), pp. 1863-1873.

[14] Y. J. Kim and Y. W. Lim, "Role of the Demographic Characteristics on the Relationship between Customer Orientation and Flight Attendants", Journal Korea Acad Industr Coop Soc, vol. 16, no. 1, (2015), pp. 346-353.

[15] F. Faul, E. Erdfelder, A. G. Lang and A. Buchner, "G*Power 3: A flexible statistical power analysis for the social, behavioral, and biomedical sciences", Behav Res Methods, vol. 39, no. 2, (2007), pp. 175191. 
[16] A. Parasuraman, V. A. Zeithaml and L. L. Berry, "SERVQUAL: A Multiple-item Scale for Measuring Consumer Perceptions of Service Quality", Journal Retailing, vol. 64, no.1, (1988), pp. 12-37.

[17] H. G. Moon, "Influence of Organizational Culture, Service Oriented Culture, and Cultural Strength on Customer Orientation of Hospital Employees", Unpublished masters's thesis, University of Inje University, Gimhae, Korea, (2003).

[18] J. D. Houghton and C. P. Neck, "The Revised Self-leadership Questionnaire: Testing a Hierarchical Factor Structure for Self-leadership”, Journal Manage Psychol, vol. 17, no. 8, (2002), pp. 672-691.

[19] J. H. Park, E. K.Yun and S. S. Han, "Factors Influencing Nurses' Organizational Citizenship Behavior", Journal Korean Acad Nurs, vol. 39, no.4, (2009), pp.499-507.

[20] Y. R. Yeun, "Job Stress, Burnout, Nursing Organizational Culture and Turnover Intention among Nurses", Journal Korea Acad Industr Coop Soc, vol. 15, no. 8, (2014), pp. 4981-4986.

[21] R. E. Quinn and M. R. McGrath, "Organizational Culture", Sage Publications, Beverly Hills, (1985).

[22] C. M. Brotheridge and R. T. Lee, "Testing a Conservation of Resources Model of Dynamics of Emotional Labor”, Journal Occup Health Psychol, vol. 7, no. 1, (2002), pp. 57-67.

[23] R. Yi, W. S. Gim and K. H. Shin, "The Role of Emotional Labor Strategies in the Job Demand-resource Model with Burnout and Engagement”, Korean Journal Ind and Organ Psychol, vol. 19, no. 4, (2006), pp. 573-596.

[24] G. L. Stewart and C. C. Manz, "Leadership for Self-managing Work Teams: A Typology and Integrative Model”, Hum Relat, vol. 48, no. 7, (1995), pp. 747-770.

[25] A. R. Hochschild, "The Managed Heart: Commercialization of Human Feeling", University of California Press, Berkeley, (1983).

[26] G. Morgan, "Accounting as Reality Construction: Towards a New Epistemology for Accounting Practice", Account Organ Soc, vol. 13, no. 5, (1988), pp. 477-485.

[27] J. S. Park, "A Study on the Influence of Organization Culture on Customer Orientation in Police", Police Science Review, vol. 22, (2009), pp. 193-219.

\section{Authors}

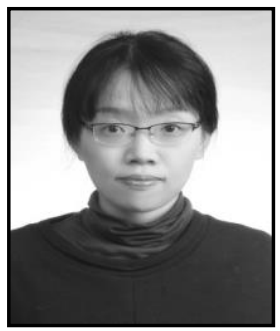

Jun Hee Park, she is a doctoral student in college of nursing science at Kyunghee University. She received the BS and MS degree from Kyunghee University, Seoul, Korea, in 2000 and 2007. Her research interests include chronic disease management and system dynamics methodology.

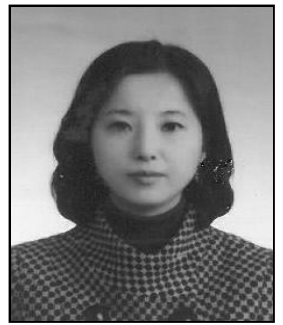

Jeong Won Han, she is an assistant professor in nursing at Kosin University. She received the BS, MS and PhD degree from Kyunghee University, Seoul, Korea, in 2002, 2011 and 2014, respectively. Her research interests center around statistical methods and colorectal cancer.

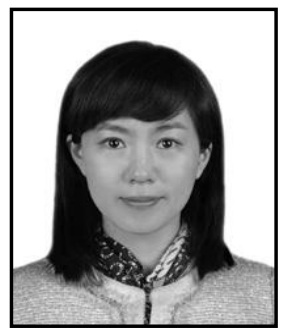

Young Ran Yeun, she is an assistant professor in the Department of nursing at Kangwon National University. She received her MPH in health promotion in 2008, and her $\mathrm{PhD}$ in nursing in 2012. Her research interests focus on identifying psychosocial risk factors for mental problems and promoting mental health. 